\title{
Kinetic analysis of enhanced biological phosphorus removal in a hybrid integrated fixed film activated sludge process
}

\author{
*B. Hooshyari; A. Azimi; N. Mehrdadi \\ Department of Environmental Engineering, Faculty of Environment, Tehran University, Tehran, Iran \\ Received 10 April 2008; ～revised 25 July 2008; accepted 18 November 2008; available online 10 December 2008
}

\begin{abstract}
Hybrid integrated fixed film activated sludge is a promising process for the enhancement of nitrification, denitrification and phosphorus removal in conventional activated sludge systems that can be used for upgrading biological nutrient removal, particularly when they have space limitations or need modifications that will require large monetary expenses. In this research, successful implementation of hybrid integrated fixed film activated sludge process at temperate zone wastewater treatment facilities has been studied by the placement of fixed film media into aerobic, anaerobic and anoxic zones. The primary objective of this study was to investigate the incorporation of enhanced biological phosphorus removal into hybrid integrated fixed film activated sludge systems and study the interactions between the fixed biomass and the mixed liquor suspended solids with respect to substrate competition and nutrient removal efficiencies. A pilot-scale anaerobic-anoxic-oxic configuration system was used. The system was operated at different mean cell residence times and influent chemical oxygen demand/total phosphorus ratios and with split influent flows. The experimental results confirmed that enhanced biological phosphorus removal could be incorporated successfully into hybrid integrated fixed film activated sludge system, but the redistribution of biomass resulting from the integration of fixed film media and the competition of organic substrate between enhanced biological phosphorus removal and denitrification would affect performances. Also, kinetic analysis of the reactor with regarding to phosphorus removal has been studied with different kinetic models and consequently the modified Stover-Kincannon kinetic model has been chosen for modeling studies and experimental data analysis of the hybrid integrated fixed film activated sludge reactor.
\end{abstract}

Key words: Nutrient removal, biomass cell, biofilm reactors, mean cell residence time, stover kincannon model

\section{INTRODUCTION}

The need to develop new technologies for phosphorus removal/recovery from wastewater has become necessary due to an increasing demand for sustainable mineral resources, more stringent discharge limits to prevent eutrophication of natural water resources and tightening sludge disposal restrictions. Phosphorus recovery for being reused by the phosphate industry and in agriculture is (Sriwiriyarata and Randall, 2005) technically feasible (although detailed economic analysis has yet to be completed) and there are a number of technologies for recovering phosphorus from wastewater originating from various sources (municipal, industrial, run-off). Several processes, including chemical and biological precipitation, crystallisation and biosorption have been developed for removal and subsequent recovery of phosphorus from wastewater (Randall and Sen, 1994;

\footnotetext{
\*Corresponding Author Email: hooshyari_b@yahoo.com
} Tel./Fax:+9821 88955592
Sen, 1995; Sen et al., 1996). These processes need complex and strict control of the operating conditions and some of them produce excess sludge that requires disposal. Furthermore, it is difficult to recover, as opposed to remove, phosphorus by these processes (Harrcmoes, 1976). During the past decade, considerable research has investigated the benefits of integrating fixed film media into biological nutrient removal (BNR) activated sludge processes with the primary objective of enhancing nitrification at low mixed liquor temperatures and mean cell residence times (MCRTs) (Mitta, 1994 ). However, few of these studies have included enhanced biological phosphorus removal (EBPR), even when anaerobic zones were included in the systems, apparently because of the very low suspended biomass MCRTs and used temperature combinations. It is known that EBPR will wash out of activated sludge systems before heterotrophic functions (McClintock et al., 1991; Mamais and Jenkins, 
1992) and that EBPR processes require that the biomass experiences sequen-cing anaerobic and aerobic conditions. Therefore, EBPR by attached biomass would not be possible in most continuous-flow BNR systems because the biomass is fixed in one location and typically can not be subjected to alternating environmental conditions (Liu, 1996). A few investigators have explored the interactions of EBPR and fixed film systems. One study attempted to implement EBPR in sequencing batch reactor (SBR) systems containing Pall rings with a total biofilm surface area of $54 \mathrm{~m}^{2}$ and evaluated at different organic loadings, cycle durations and aerobic hydraulic retention times (Garzon-Zuniga and Gonzalez-Martinez, 1996). The optimum performances as indicated by experimental results for simultaneous organic carbon, nitrogen and phosphorus removal were achieved at $3 \mathrm{~g} \mathrm{COD} / \mathrm{m}^{2} /$ day organic loading using a $24 \mathrm{~h}$ cycle period. The alternating ratio of anaerobic/aerobic conditions of 1.0/1.0 provided the best results. Helness and Ødegaard (1999) concluded that good and stable EBPR could be achieved in a $10 \mathrm{~L}$ moving bed biofilm SBR filled with $53 \%$ by volume Kaldnes-media if it was subjected to alternating anaerobic and aerobic conditions. The factors affecting EBPR were the length of the anaerobic period which must be long enough to completely remove the readily biodegradable chemical oxygen demand (COD) and the COD loading rates which must be high enough for growth of biomass in the reactor. They concluded that the EBPR potential in hybrid biofilm/activated sludge systems was likely to be as good as in purely suspended growth activated sludge systems. Thus, although it is very unlikely that EBPR would be possible by biofilms growing in continuous-flow BNR systems with fixed environmental zones, it is reasonable that EBPR could be maintained in hybrid integrated fixed film activated sludge (H-IFAS) systems where much of the biomass is in suspended form and circulates throughout the system. The objective of this research was to demonstrate the ability of such systems to accomplish EBPR and to do the kinetic analysis of the process for determination of the reactor biological phosphorus removal design criteria (Henze and larremoes, 1983). This research was conducted in Ekbatan waste water treatment plant (WWTP) in Tehran, Iran from 12 July 2005 to 12 March 2006.

\section{MATERIALS AND METHODS}

Reactor system

As shown in Fig. 1, the H-IFAS reactor was set up at
Ekbatan WWTP in Tehran, Iran. The system comprised an anaerobic (300 L), an aerobic (850 L), two anoxic zones (850 L) and a clarifier. The raw wastewater was fed to an elevated storage tank by a centrifuge pump from the grit chamber downstream and raw wastewater is fed to the reactor in an upflow manner. In order to control the content of media in each zone, some stainless steel meshes were installed between these parts. The aerobic and anoxic zones were separated with an impermeable metallic wall. Of course the above part of the walls consisted of some meshes which direct the flow to the anoxic zones. All anaerobic, aerobic and anoxic zones were filled up with moving media and in anoxic zones two mixers were used for provision of a complete mixing. The wastewater and the air flow were supplied in a concurrent manner to ensure proper contact time. Aeration was supplied with a side channel blower and aeration rate was measured and monitored by an air flowmeter. In the meantime, a wastewater flowmeter is used to define the flow of influent raw wastewater which was fed to the reactor in each condition. The rate of return sludge from the clarifier was controlled and monitored by a full automatic timer which controlled the flow and time of sludge returning in each phase. Two centrifugal pumps were used for transferring raw wastewater to the storage tank and another one for returning sludge to the anaerobic zone. The H-IFAS reactor was based on integrated (attached and suspended) biomass technology for acidification, nitrification, denitrification and phosphorus removal. The anaerobic zone of the H-IFAS reactor was constructed as a high-rate anaerobic reactor filled up with Bee-Cell 2000 moving media where the complex organics compounds from the wastewater were converted to readily biodegradable components. According to media technical specifications and bench scale and pilot-plant studies the media fill fraction in anaerobic, aerobic and anoxic zones was selected $60 \%, 50 \%$ and $50 \%$, respectively. A recycling flow from anoxic zone is directed to aerobic zone for alkalinity recovery and $\mathrm{pH}$ adjustment in aerobic zone. The experiments were implemented in nine phases based on media locations, media quantities and COD/TP/TKN ratios. As it was shown in Table 2, Bee-Cell 2000 media was chosen as the fixed film biocarrier for this investigation which is made of high impact polystyrene and is specifically designed with a high internal (protected) specific surface area to maximize attached growth potential, but with sufficient void space to 
minimize plugging. The media consists of two concentric cylinders connected by internal walls along the length of the media. The overall dimensions are $22 \mathrm{~mm}\left(0.9^{\prime \prime}\right)$ in diameter and $15 \mathrm{~mm}\left(0.6^{\prime \prime}\right)$ in length. The internal surface area is $388 \mathrm{~m}^{2} / \mathrm{m}^{3}\left(120 \mathrm{ft}^{2} / \mathrm{ft}^{3}\right)$ and total surface area is 650 $\mathrm{m}^{2} / \mathrm{m}^{3}\left(198 \mathrm{ft}^{2} / \mathrm{ft}^{3}\right)$. Only the protected internal surface area is considered for design purposes.

\section{Wastewater characteristics}

Influent raw wastewater characteristics have been given in Table 1. These data which was adopted from the wastewater company's laboratory information were related to raw wastewater characteristics which were pumped from the downstream of the grit chamber of the Ekbatan WWTP.

Table 1: Bee-Cell 2000 moving media specifications

\begin{tabular}{ll}
\hline Technical specifications & Bee-Cell 2000 \\
\hline Material & Polystyrene, high impact \\
Specific surface area & $650 \mathrm{~m}^{2} / \mathrm{m}^{3}\left(198 \mathrm{ft}^{2} / \mathrm{ft}^{3}\right)$ \\
Maximum fill & Up to $75 \%$ \\
Weight per $\mathrm{m}^{3}$ & Max. $140 \mathrm{~kg} / \mathrm{m}^{3}$ \\
Number of units per $\mathrm{m}^{3}$ & 361,000 \\
Surface per unit & $18 \mathrm{~cm}^{2}$ \\
Percentage of hollow space & $87 \%$ \\
Color & Natural white \\
\hline
\end{tabular}

\section{Experimental setup}

The reactor was operated during 9 phases in 8 months (from 12 July 2005 to 12 March 2006) and 46 composite samples were collected, tested and analyzed for measuring physical, chemical and bacteriological parameters of aerobic, anaerobic and anoxic zones effluent. All experiments in 9 phases were conducted in a quasy steady state condition. Raw wastewater qualitative and quantitative data was adopted from Ekbatan WWTP laboratory information. The methods of sampling and different experiments were quite the same as the ones were used in the research.

The systems were operated and monitored for over 8 months to allow them to reach steady state conditions and then at least three runs of steady state data were collected from each system during each phase of experiments to characterize each of them. At steady state, COD, total Kjeldahl nitrogen (TKN), total phosphorus (TP), anions (nitrite, nitrate and phosphate) and cations (ammonia-N) were measured. TKN, TP and COD were analyzed in accordance with standard methods for the examination of water and wastewater, $20^{\text {th. }}$ Ed., 1998 (APHA, AWWA and WEF, 1995).

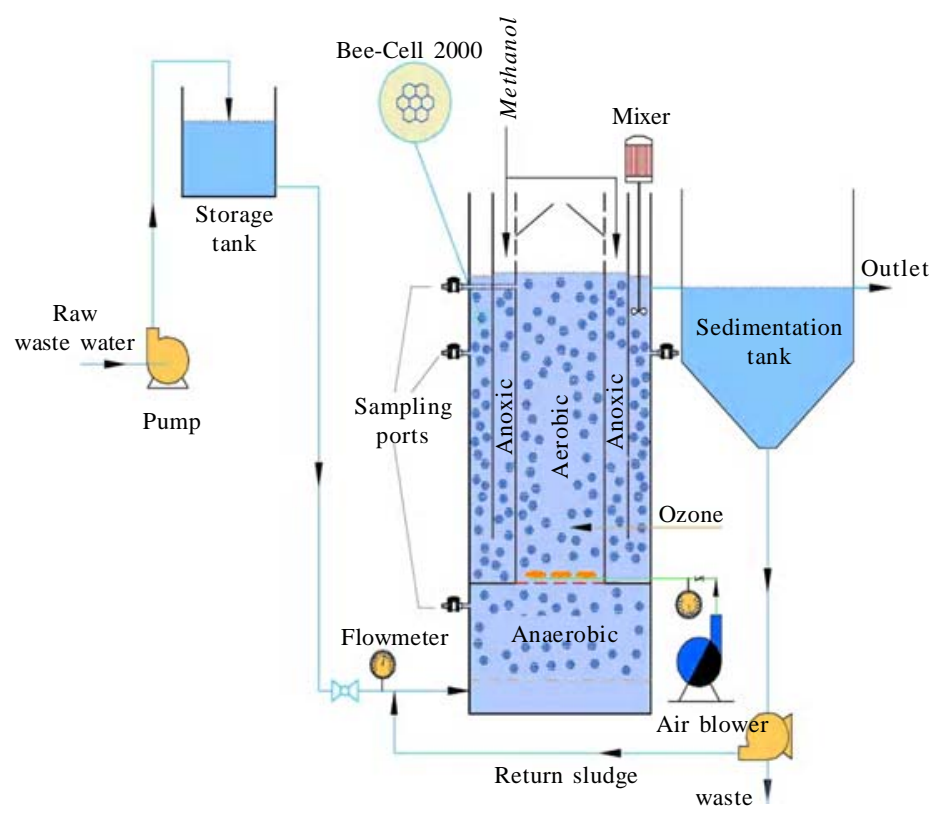

Fig. 1: The schematic of H-IFAS reactor 
Kinetic analysis of enhanced biological phosphorus removal

Table. 2: Raw wastewater characteristics

\begin{tabular}{|c|c|c|c|c|c|c|c|c|c|c|c|c|c|}
\hline \multirow{2}{*}{ Parameters } & \multirow[b]{2}{*}{ Apr. } & \multicolumn{7}{|c|}{2005} & \multicolumn{5}{|c|}{2006} \\
\hline & & May & Jun. & Jul. & Aug. & Sep. & Oct. & Nov. & Dec & Jan. & Feb. & Mar. & Aug. \\
\hline $\mathrm{T}\left({ }^{\circ} \mathrm{C}\right)$ & 21.1 & 25.6 & 25.6 & 26.1 & 26 & 26.5 & 25 & 22 & 22 & 21 & 22 & 22 & 24 \\
\hline $\mathrm{pH}$ & 7.47 & 7.77 & 7.71 & 7.79 & 7.8 & 7.73 & 7.8 & 7.9 & 7.7 & 7.7 & 8 & 7.8 & 7.8 \\
\hline TS (mg/|L) & 661 & 569 & 625 & 657 & 667 & 649 & 613 & 657 & 665 & 704 & 660 & 763 & 658 \\
\hline TSS (mg/L) & 180 & 236 & 252 & 206 & 211 & 197 & 200 & 200 & 180 & 205 & 143 & 219 & 202 \\
\hline $\mathrm{BOD}_{5}(\mathrm{mg} / \mathrm{L}$ & 171 & 170 & 143 & 154 & 148 & 170 & 115 & 148 & 158 & 155 & 85 & 195 & 151 \\
\hline $\operatorname{COD}(\mathrm{mg} / \mathrm{L})$ & 222 & 312 & 245 & 234 & 220 & 245 & 259 & 189 & 180 & 269 & 285 & 237 & 243 \\
\hline TKN (mg/L) & 45 & 46 & 42 & 47 & 46 & 47 & 48 & 46 & 47 & 40 & 43 & 40 & 45 \\
\hline $\mathrm{TP}(\mathrm{mg} / \mathrm{L})$ & 9.55 & 16.1 & 12.2 & 14 & 15 & 4.33 & 13 & 13 & 13 & 12 & 10 & 8.9 & 12 \\
\hline
\end{tabular}

\section{Analytical procedure}

The systems were operated and monitored for about 2 months allowing them to reach steady state conditions and then at least three runs of steady state data were collected from each system during each phase of experiments to characterize each of them. At steady state, mixed liquor suspended solid (MLSS), mixed liquor volatile suspended solid (MLVSS), COD, TKN, TP, anions and cations (ammonia-N, potassium, magnesium, and calcium) were measured. The MLSS, MLVSS, TKN, TP and COD were analyzed in accordance with Standard methods for the examination of water and wastewater, $19^{\text {th }}$ Ed., 1995. Anions were analyzed using a Dionex 2010I Ion chromatograph (IC) with an IONPAC AS4A-SC column and electrochemical conductivity detector (Dionex Corp., Sunnyvale, CA). Cations were analyzed using a Dionex 120 ion chromatography (Dionex Corp., Sunnyvale, CA). Liquid samples for total phosphorus were frozen immediately after collection. Samples of process suspended solids were separated from the liquid immediately after collection by filtering through Whatman glass fiber filters to be analyzed for percent phosphorus by weight. The solid residue was ovendried at $104^{\circ} \mathrm{C}$ and then finely ground for analysis. Analysis for total phosphorus was conducted on a Lachat QuikChem Automated Ion Analyzer according to QuikChem method No. 10-115-01-1-C. The percentage of volatile solids was calculated and then used to determine the total volatile solids on the media. Solid retention time (SRT) or sludge age was determined by measuring the average residence time of the suspended microorganisms (suspended biosludge) in the system. $\mathrm{F} / \mathrm{M}$ was presented as a ratio of $\mathrm{BOD}_{5}$ loading and the total biosludge of the system.

\section{RESULTS AND DISCUSSION}

Biomass growth on the fixed film media in the H-IFAS systems resulted in significant biomass redistributions and affected the total amounts of biomass maintained in the system. H-IFAS reactor affected both the concentrations and amounts of biomass in the reactor and the total amounts of biomass maintained in the system. It was assumed that VS determinations would not measure the inorganics and any differences in VS would reflect metabolic differences in the system (Rozzi and Verstraete, 1981). Also, the biofllm solids were converted to volatile suspended solids (VSS) for addition with the activated sludge mixed liquor volatile suspended solids so that the biomass concentrations could be expressed uniformally. The data clearly showed that installation of fixed film media increased the amounts of MLVSS maintained in the H-IFAS reactor compared to the activated sludge process thereby increasing the mass fraction in H-IFAS system and possibly increasing its potential for EBPR. As it is shown in Fig. 2, biological phosphorus removal rate of the reactor at optimized operational conditions with a phosphorous loading rate of $243.57 \mathrm{~g} \mathrm{P}-\mathrm{PO} 4 / \mathrm{m}^{3} /$ day , an average temperature of $23.48^{\circ} \mathrm{C}$ and $\mathrm{HRT}=27 \mathrm{~min}$ was equal to $168.4 \mathrm{~g} \mathrm{P}-$ $\mathrm{PO} 4 / \mathrm{m}^{3} /$ day. The rate of return sludge from the clarifier was controlled and adjusted by an automatic timer and the effect of returning sludge rate on the efficiency of phosphorous removal in the reactor was studied as well. It was shown that the best result for P removal efficiency occurred when the rate of sludge return was about $15 \%$ of the influent flowrate.

\section{Phosphorus removal kinetics}

The removal of phosphorus by heterogeneous microorganisms in the reactor can be determined on the basis of the phosphorus removal rate as a function 
of the phosphorus concentration (Hobson, 1983). Such a relationship for the result of the present study is shown in Fig. 3 showing that the phosphorus removal rate increased with decrease in phosphorus concentration. There are several models which have been used to describe the overall kinetics of biological reactors. Two models assume a steady-state relationship of the form (Mamais and Jenkins, 1992).

$\frac{d S}{d t}=\frac{Q}{V}\left(S_{i}-S_{e}\right)$

Where dS/dt is defined in two ways as follows:

$$
\begin{aligned}
& \frac{d S}{d t}=\frac{U_{\max }\left(Q S_{i} / V\right)}{K_{B}+\left(Q S_{i} / V\right)} \\
& \frac{d S}{d t}=\frac{k X S_{e}}{K_{s}+S_{e}}
\end{aligned}
$$

Eq. 3 is a monod model while equation 2 results from a simple modification of stover-Kincanon model proposed for rotating biological contactor (RBC) systems (Kincanon and Stover, 1982; Shieh, 1982).The original Stover-Kincanon model is:

$$
\frac{d S}{d t}=\frac{U_{\max }\left(Q S_{i} / A\right)}{K_{B}+\left(Q S_{i} / A\right)}
$$

In the original Stover-Kincanon model, the disc surface area (A) is used to represent some relationship in the total attached growth active biomass concentration in an RBC assuming that the suspended (2) biomass in the RBC system is negligible in comparison to the attached biomass (Wilson, 1993; Jensen, 1995). However, for a biofilm reactor such as anaerobic filters (Lindgren, 1983; Yang et al., 1987; Tilche and Vieiga, (3) 1991) the volume (V) of the biofilm reactor is used

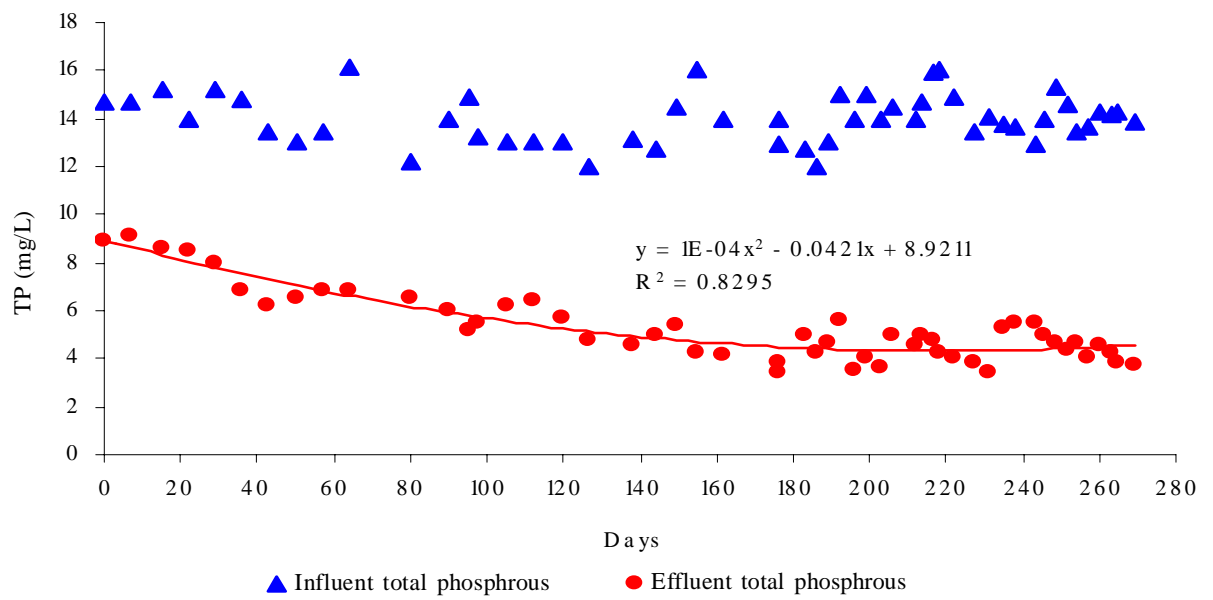

Fig. 2: Phosphorous removal rate at different phases of H-IFAS reactor operation

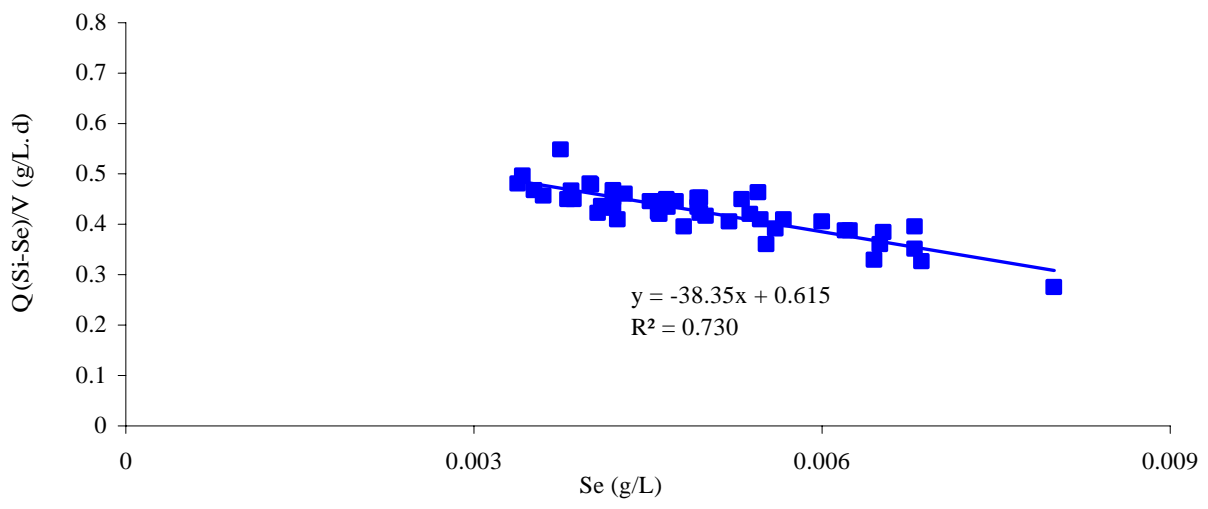

Fig. 3: Phosphrus removal rate versus substrate concentration 
instead of the surface area (A) of the support media (Suidan and Wang, 1985).

Biofilm reactor operates through contact processes in which wastewater passes through a bed of biomass either as a biofilm attached on the fixed media or as a mass of suspended growth solids within the bed. A recent investigation by Tay et al., (1996) demonstrated that the suspended biomass in biofilm reactors contributes approximately one half of the total waste removal. Therefore, the volume of the biofilm reactor is used instead of the surface area of the support media for H-IFAS reactor in this study (Flora et al., 1995).

The major difference between the Stover-Kincannon model and the Monod model is the introduction of the concept of total organic loading rate, QSi/V, to the Stover-Kincanon model. According to Kincannon and Stover (1982), both hydraulic loading rate and organic concentration exhibit definite relationships with phosphorus removal rate and efficiency. Some research results (Kincannon and Stover, 1982) have shown that the removal rate and efficiency are dependent on the amount of total organics applied to biological reactors rather than organic concentrations or hydraulic loading rate (HLR). The amount of organics removed by such systems is the same. For the same loading rate, regardless of whether the loadings are accomplished by a low HLR at a high concentration or a high HLR at a low organic concentration (Srivastava, 1995).

\section{Stover-Kincanon model}

Fig. 4 illustrates the result of plotting specific phosphorus removal rate $\mathrm{Q}\left(\mathrm{S}_{\mathrm{i}}-\mathrm{S}_{\mathrm{e}}\right) / \mathrm{V}$ versus total loading rate $\mathrm{QS}_{\mathrm{i}} / \mathrm{V}$ for the all experimental results.

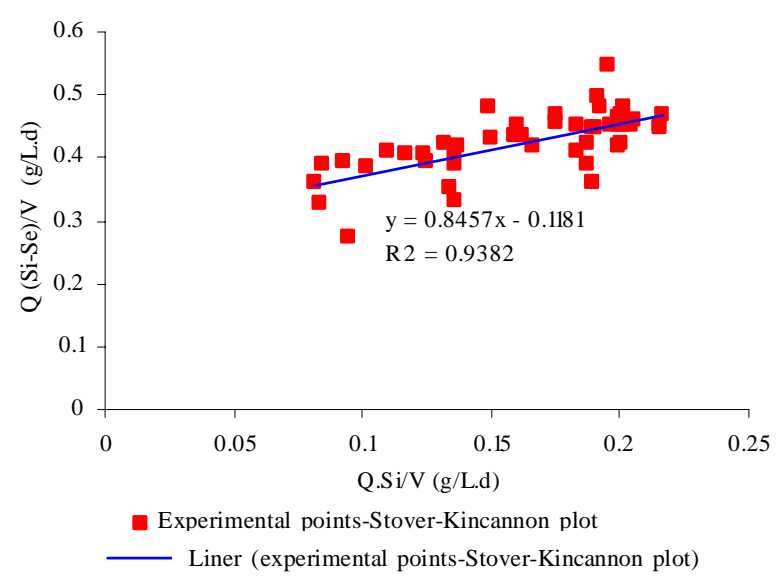

Fig. 4: Removal loading rate versus total loading rate with Stover-Kincanon curve and Eq. 13
The major feature of the graph is the gradual increase of efficiency with increasing loading rate. Linearization of Eq. 2 gives the following relationship:

$$
\frac{d S}{d t}=\frac{V}{Q\left(S_{i}-S_{e}\right)}=\frac{K_{B}}{U_{\max }} \cdot \frac{V}{Q S_{i}}+\frac{1}{U_{\max }}
$$

Where, dS/dt is the phosphorus removal rate (g/ L.d); $\mathrm{S}$ is the reactor phosphorus concentration $(\mathrm{g} / \mathrm{L})$; $\mathrm{U}_{\max }$ is the maximum removal rate constant (g/L.d) and $K_{B}$ is a saturation value constant (g/L.d). If (dS/ $\mathrm{dt})^{-1}$ is taken as WQ[( $\left.\left.\mathrm{S}_{\mathrm{i}}-\mathrm{S}_{\mathrm{e}}\right)\right]$, which is the inverse of the loading removal rate and this is plotted against the inverse of the total loading rate $\mathrm{V} /\left(\mathrm{QS}_{\mathrm{i}}\right)$, a straight line portion of intercept rate $1 / \mathrm{U}_{\max }$ and a slope of $\mathrm{K}_{\mathrm{B}} / \mathrm{U}_{\max }$ are resulted. This plot is shown in Fig. 5 from which $\mathrm{K}_{\mathrm{B}}$ and $\mathrm{U}_{\max }$ can be estimated as $2.51 \mathrm{~g} /$ L.d and $2.053 \mathrm{~g} / \mathrm{L}$.d, respectively. The regression line had a $\mathrm{R}^{2}$ of 0.9107 confirming the applicability of Eq. 2. The $U_{\max }$ and $K_{B}$ values obtained in Fig. 5 can be used to determine the volume required to decrease the influent phosphorus concentration from $S_{i}$ to $S_{e} r$ to determine the effluent phosphorus concentration for a given $\mathrm{V}$ and $\mathrm{S}_{\mathrm{i}}$. If a volume of the H-IFAS reactor where the mass of phosphorus into the volume of media plus the mass of phosphorus biodegraded is considered, then a mass balance of phosphorus into and out of the volume can be made as follow:

$$
Q S_{i}=Q S_{e}+V\left(\frac{d S}{d t}\right)
$$

Relationship 5 for $\mathrm{dS} / \mathrm{dt}$ can be substituted giving as following:

$Q S_{i}=Q S_{e}+\left(\frac{U_{\max }\left(Q S_{i} / V\right)}{K_{B}+\left(Q S_{i} / V\right)}\right) V$

This expression can then be solved for either the required volume of the reactor or the effluent concentration.

$$
\begin{aligned}
& V=\frac{Q S_{i}}{\left(U_{\max } S_{i} / S_{i}-S_{e}\right)-K_{B}} \\
& S_{e}=S_{i}-\frac{U_{\max _{x}} S_{i}}{K_{B}+\left(Q S_{i} / V\right)}
\end{aligned}
$$

Introduction of the values of $\mathrm{K}_{\mathrm{B}}(2.51 \mathrm{~g} / \mathrm{l} . \mathrm{d})$ and $\mathrm{U}_{\max }$ $(2.053 \mathrm{~g} / \mathrm{L} . \mathrm{d})$ to relationship produces:

$S_{e}=S_{i}-\frac{2.053 S_{i}}{2.51+Q S_{i} / V}$ 
Eq. 10 can be employed to calculate the effluent organic concentration at a given organic concentration for the lab-scale biofilm reactor treating municipal wastewater (McCarty and Mosey, 1991). Monod model linearization of Eq. 2 (Monod model) results in:

$\frac{X V}{Q\left(S_{i}-S_{e}\right)}=\frac{K_{s}}{k} \cdot \frac{1}{S_{e}}+\frac{1}{k}$

Where $\mathrm{K}$ is the maximum rate of phosphorus utilization $\left(\mathrm{d}^{-1}\right) ; \mathrm{K}_{\mathrm{s}}$ is half-velocity constant $(\mathrm{g} / \mathrm{L})$ and $\mathrm{X}$ is the microorganism concentration of VSS in the reactor $(\mathrm{g} / \mathrm{L})$.

The attached biomass was obtained by putting some bunched of the support media into the column and taking a bunch of the media out of the reactor in a definite period of the time by washing them and weighing the detached mass both in wet and dry conditions. The suspended biomass was extracted through the sampling points and subsequently weighed. The value of $\mathrm{X}$ was the sum of the suspended biomass concentration (Song and Young, 1986). A plot of Eq. 11 provides the necessary information for Monod kinetic coefficients in the treatment of municipal wastewater in H-IFAS reactor. Using all the steady-state operational experimental results, Eq. 11 is plotted in Fig. 6. The $\mathrm{R}^{2}$ of 0.790 being lower than that for the modified Stover-Kincannon model. This indicates that the modified StoverKincannon model (Eq. 2) is a more appropriate model for describing the kinetics of the reactor treating municipal wastewater .

The result of plotting the removed loading rate versus the total loading rate is illustrated in Fig. 3 with the modified Stover-Kincannon relationship (Eq. 2) being plotted as a curve $\left(\mathrm{K}_{\mathrm{B}}=2.51 \mathrm{~g} / \mathrm{L}\right.$.d and $\left.\mathrm{U}_{\max }=2.053 \mathrm{~g} / \mathrm{L} . \mathrm{d}\right)$. The predicted values using Eq. 13 and the experimental results are also shown in Fig. 3. The modified Stover-Kincannon relationship seemed to be better predictor compared with Eq. 13. Three considerations arise out of Figs. 3 and 5. Firstly, the Stover-Kincannon model seems to be applicable not only to aerobic fixed-film reactors, but also to anaerobic filters. This relationship was first proposed and applied to the trickling filter (Kincannon and Stover, 1982) and then to RBCs. The total loading concept used in the model has been found to be applicable to various wastewters such as domestic sewage (Stover and Kincannon, 1982). Slaughterhouse wastewater filters
(Kincannon and Stover, 1982), pulp and paper wastewater (Stover and Kincannon, 1982), pickle wastewater (Wilson et al., 1988 ) and high-strength organic wastewater (Wilson ,1993; Wilson and Lee, 1995). In the H-IFAS reactor, the combination of aerobic and anaerobic zones in one reactor provides the conditions of an efficient biological phosphorus removal. Anaerobic treatment processes do not share exactly same degradation pathways as aerobic processes. The anaerobic digestion process basically has five steps: Hydrolysis, fermentation of amino acids, anaerobic oxidation of long chain fatty acids and alcohols, anaerobic oxidation of short chain fatty acids, homoacetogenesis and methanogenesis. Hence, the kinetics of the anaerobic process are more complex than those of aerobic process. However, the present study confirms that the Stover-Kincannon model can also be applied to the kinetic analysis of the anaerobic filter. The concepts and methodology used in the Stover-Kincannon model appear to be applicable to the other fixed-film reactors, irrespective of the treatment under aerobic or anaerobic condition.

In addition, one advantage of the StoverKincannon model is the capability to predict

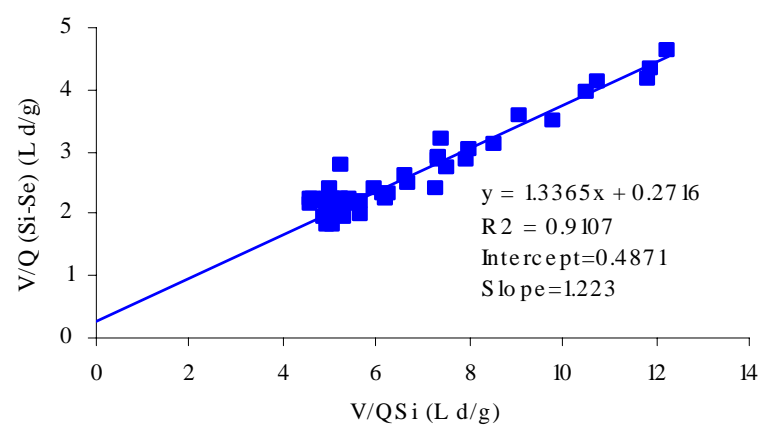

Fig. 5: Stover-Kincanon model plot

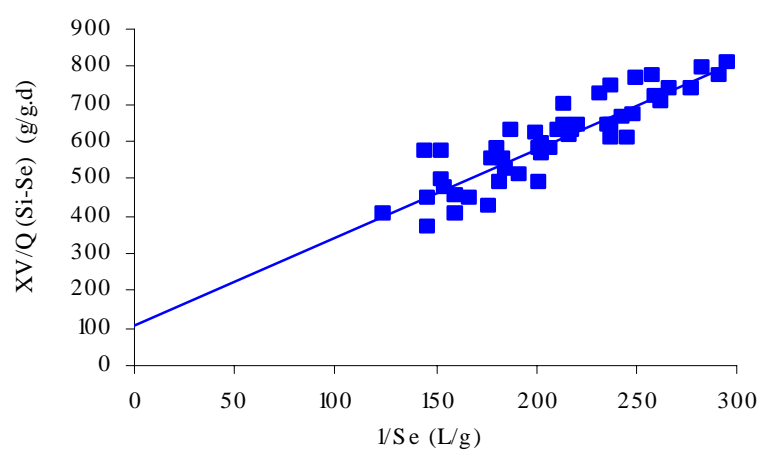

Fig. 6: Monod model plot 
phosphorus removal and treatment efficiency at any loading condition, irrespective of zero, first or second order kinetics. Secondly, it is recognized that the Stover-Kincannon model does not model phosphorus diffusion, hydraulic dynamics and other parameters. These other parameters may be important in the overall performance of fixed-film reactors. However, at the present time, they are difficult to measure them and therefore their effects are difficult to be modeled. It seems that at the present time, the Stover-Kincannon model is more useful without these types of parameters. Thirdly, the volume of the biofilm reactor $(\mathrm{V})$ can be used instead of the surface area of the support media (A) in the Stover-Kincannon model describing the reactor. In the other studies which used the StoverKincannon model, A has been always used to represent the biomass concentration. However, as mentioned previously, replacing $\mathrm{A}$ by $\mathrm{V}$ in this study gave rise to the high values of $\mathrm{R}^{2}$ of Eq. 4 . Hence, it is felt that $\mathrm{V}$ is an appropriate parameter in the Stover-Kincannon model. If $\mathrm{Q}\left(\mathrm{S}_{\mathrm{i}}-\mathrm{S}_{\mathrm{e}}\right) / \mathrm{V}$ is taken to be the reaction rate, then the reaction order (i.e the exponent of $\mathrm{S}_{\mathrm{e}}$ ) is approximately 0.790 . Therefore, the reaction order appeared to be close to half order. The major difference between Eqs. 14 and 15 is that the latter indicates HLR should also be considered when determining the reaction order of the reactor. This suggests that Eq. 15 is a more appropriate model in determining the reaction order of the reactor treating municipal wastewater. Consequently, the reaction order appeared to be close to half order. Harrcmoes (1976) and Shieh (1982) have predicted that an intrinsic zero order reaction occurring in an aerobic biofilm will show an overall half reaction for the case where external transfer limitation is insignificant and Shieh (1982) has shown that other researchers results for nitrite removal in RBCs confirm this finding.

A comparison of the measured and predicted final effluent data is presented in Fig.7. The high correlation between the two parameters also confirms that Stover-Kincannon model is appropriate for characterizing phosphorus removal in H-IFAS reactor.

\section{CONCLUSION}

The results of this investigation clearly show that EBPR can be successfully accomplished in H-IFAS systems. It was statistically confirmed that EBPR could be maintained in the H-IFAS systems without serious complications. The EBPR performance in the H-IFAS process with media installed in the anoxic zone to which influent flow came from the aerobic zone and the presence of readily biodegradable COD of the biomass in the anoxic zone stimulated the attached biofilms to release phosphorus. Thus, a considerable part of the flow was come back to the aerobic zone where they could take up the released phosphorus during stored substrate utilization. The phosphorus release and uptake took place in different amounts in each phase of the reactor operation and biological phosphorus removal rate of the reactor at optimized operational conditions with a phosphorous loading rate of 243.57 g P-PO4 $/ \mathrm{m}^{3} /$ day, an average temperature of $23.48{ }^{\circ} \mathrm{C}$ and $\mathrm{HRT}=27 \mathrm{~min}$ was equal to $168.4 \mathrm{gP}-\mathrm{PO} 4 / \mathrm{m}^{3} / \mathrm{day}$.

The phosphorus loading removal rate was compared with predictions from a modified Stover-Kincannon

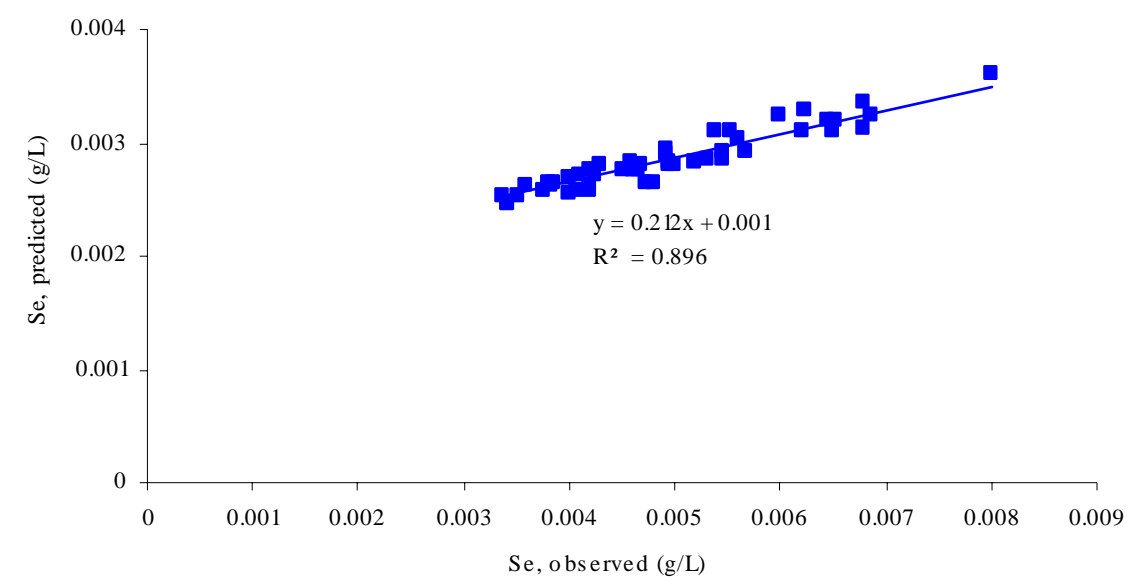

Fig. 7: Comparison of the measured and predicted phosphorus concentrations in the effluent 
model, the Monod model and a regression relationship. The modified Stover-Kincannon model seemed to be the best model to describe the phosphorus loading removal rate of the H-IFAS reactor treating municipal wastewater. The phosphorus removal kinetics was found to be dependent on the applied substrate loading rate. This modified Stover-Kincannon model could also be used to determine the volume required to decrease the influent phosphorus concentration to effluent concentration or to determine the effluent phosphorus concentration for a given volume of an H-IFAS reactor and influent phosphorus concentration. The maximum utilization rate constant (Umax) and saturation value constant (KB) in this model were calculated as 2.053 g/L.d and = $2.51 \mathrm{~g} / \mathrm{L} . \mathrm{d}$, respectively.

\section{ACKNOWLEDGEMENTS}

This research was supported by grant of Presidency's Researchers Supporting Organization. The authors would like to acknowledge Mr. Ghorbani, Tehran Water and Wastewater Co. managing director for sincere cooperation in this research and thank Dr. A. Torabian for his helps in theoretical aspects of the research.

\section{REFERENCES}

APHA; AWWA; WEF, (1995). Standard methods for the examination of water and wastewater. $19^{\text {th. }}$ (ed.) Washington, DC, USA.

Flora, J. R. V.; Suidan, M. T.; Biswas, P.; Sayles, G. D., (1995). A modeling study of anaerobic biofilm systems: Detailed biofilm modeling., Biotech. Bioeng., 46 (1), 43-53.

Garzon Zuniga, M.; Gonzalez Martinez, A., (1996). Biological phosphate and nitrogen removal in a bioûlm sequencing batch reactor., Water Sci. Tech., 34 (1-2), 293-301.

Harrcmoes, P., (1976). The significance of pore diffusion to filter denitrification., J. Water Pollut. Con. F., 48 (2), 377388.

Helness, H.; Ødegaard, H., (1999). Biological phosphorus removal in a sequencing batch moving bed bioûlm reactor., Water Sci. Tech., 40 (4-5), 161-168.

Henze, M.; larremoes, P., (1983). Anaerobic treatment of wastewater in fixed film reactors., Lit. Rev. water Sci. Tech., 15 (8-9), 1-101.

Hobson, P. N., (1983). The kinetics of anaerobic digestion of farm wastes., J. Chem. Tech. Biotech., 33B, 1-20.

Kincannon, D. F.; Stover, E. L., (1982). Design methodology for fixed film reaction-RBCs and biological towers. Civil Engineering for Practicing and Design Engineers, 2 (3), 107-124. Pergamon Press. New York.

Jensen, K. R., (1995). Effects of integrated fixed film activated sludge on nitrogen removal in biological nutrient removal systems. M S Thesis, Virginia Tech, Blacksburg, VA 24061.

Lindgren, M., (1983). Mathematical modeling of the anaerobic filter process., Water Sci. Tech., 15 (8-9), 197-208.
Liu, H., (1996). Utilization of captor sponges to maintain nitrification and denitrification in BNR- activated sludge at low aerobic MCRTs., MS Thesis, Virginia Tech, Blacksburg, VA 24061.

Mamais, D.; Jenkins, D., (1992). The effects of MCRT and temperature on enhanced biological phosphorus removal., Water Sci. Tech., 26 (5-6), 955-965.

McCarty, P. L.; Mosey, F. E., (1991). Modeling of anaerobic digestion processes(a discussion of concepts)., Water Sci. Tech., 24 (8), 17-33.

McClintock, S.; Randall, C. W.; Pattarkine, V., (1991). The effects of temperature and mean cell residence time on enhanced biological phosphorus removal., Proceedings, Specialty Conference on Environmental Engineering, ASCE, J. Environ. Eng., 319-324.

Mitta, P. R., (1994). Utilization of ûxed ûlm media in BNR activated sludge. MS Thesis, Virginia Tech, Blacksburg, VA 24061.

Randall, C. W.; Sen, D., (1996). Full-scale evaluation of an integrated fixed-film activated sludge (IFAS) process for enhanced nitrogen removal., Water Sci. Tech., 33 (12), 155-162.

Rozzi, A.; Verstraete, W., (1981). Calculation of active biomass and sludge production vs waste composition in anaerobic contact process., Tribol. Cebedeau, 34 (455), 421-427.

Sen, D., (1995). COD removal, nitrification, and denitrification kinetics and mathematical modeling of an integrated fixed film activated sludge (IFAS) system. Ph.D thesis, Dept. Civil Environ. Eng., Virginia Tech., Blacksburg, VA 24061.

Sen, D.; Mitta, P.; Randall, C. W., (1994). Performance of fixed film media integrated in the activated sludge reactors to enhance nitrogen removal., Water Sci. Tech., 30 (11), 13-24.

Shieh, W. K., (1982). Mass transfer in a rotating biological contactor., Water Res., 16 (4), 1971- 1974.

Song, K. H.; Young, J. C., (1986). Media design factors for fixed bed filters., J. Water Pollut. Con. Fed., 58 (2), 115121.

Srivastava, R. C., (1995). Kinetics of fresh water hyacinth digestion in semi-continuous operation., Chem. Eng. J. B., 56 (3), $100-121$.

Sriwiriyarata, T.; Randall, C. W., (2005). Performance of IFAS wastewater treatment processes for biological phosphorus removal., J. Water Res., 39 (16), 3873-3884.

Stover, E. L.; Kincannon, D. I., (1982). Rotating biological contactor scale-up and design., Proc. of the $1^{\text {st. International }}$ Conference on fixed film Biological Processes, 1-21 Kings Island. Ohio.

Suidan, M. T.; Wang, Y. T., (1985). Unified analysis of biofilm kinetics., J. Environ. Eng., 111 (5), 634 -642.

Tay, J. H.; Show, K. Y.; Jeyaseelan, S., (1996). Effects of media characteristics on performance of upflow anaerobic packed-bed reactors., J. Environ. Eng., 122 (6), 469-476.

Tilche, A.; Vieiga, S. M. M., (1991). Discussion report on reactor design of anaerobic filters and sludge bed reactors. Water Sci. Tech., 24 (8), 193-206.

Wilson, F., (1993). Prediction of rotating biological contactor efficiency using TOC., J. Environ. Eng., 119 (3), 478492. 
Wilson, F.; Hamoda, M. F.; Islam, H.; Buranasiin, P., (1988). The treatment of high strength vegetable pickling waste using the RBC process., Enviro. Tech. Lett., 9 (11), 12011212.

Wilson, F.; Lee, W. M., (1995). Rotating biological contactor for wastewater treatment in an equatorial climate., Water Sci. Tech., 35 (8), 177-184.
Yang, B. C.; Jahan, K.; Young, J. C., (1987). Modeling of anaerobic filter performance. Proc.of $8^{\text {th }}$ International Conferenc on alternative Energy Sources, 214-220, Miami Beach. FL, USA.

\section{AUTHOR (S) BIOSKETCHES}

Hooshyari, B., Department of Environmental Engineering, Faculty of Environment, Tehran University, Tehran, Iran. Email: hooshyari_b@yahoo.com

Azimi, A., Assistant professor, Department of Environmental Engineering, Faculty of Environment, Tehran University, Tehran, Iran. Email: aaazimi@chamran.ut.ac.ir

Mehradadi, N., Associate professor, Department of Environmental Engineering, Faculty of Environment, Tehran University, Tehran, Iran. Email: mehrdadi1@yahoo.com

This article should be referenced as follows:

Hooshyari, B.; Azimi, A.; Mehradadi, N., (2008). Kinetic analysis of enhanced biological phosphorus removal in a hybrid integrated fixed film activated sludge process. Int. J. Environ. Sci. Tech., 6 (1), 149-158. 